\title{
A Leader's Perspective: Using Qualitative Methodology for Program Evaluation in a Rural Middle School
}

\author{
Matthew A. Birdwell \\ Perryton Independent School District, Perryton, TX, USA \\ Email:mbirdwell@perrytonisd.com
}

How to cite this paper: Birdwell, M. A. (2018). A Leader's Perspective: Using Qualitative Methodology for Program Evaluation in a Rural Middle School. Open Journal of Leadership, 7, 19-32. https://doi.org/10.4236/oj1.2018.71002

Received: January 12, 2018

Accepted: March 3, 2018

Published: March 6, 2018

Copyright $\odot 2018$ by author and Scientific Research Publishing Inc. This work is licensed under the Creative Commons Attribution International License (CC BY 4.0).

http://creativecommons.org/licenses/by/4.0/

\section{(c) (7) Open Access}

\begin{abstract}
The purpose of this study was to analyze the male student population at West Texas Middle School in order to determine why the majority of male students at West Texas Middle School do not participate in the athletic program. This particular study was classified as both a case study and a program evaluation due to the nature of the study containing elements of both paradigms. The instruments that the researcher used to collect data were student questionnaires, structured interviews, formal observations, and attendance/academic data documents. A questionnaire was selected for data collection because of the possibility for collecting rich data straight from the student population. Structured group interviews were conducted in order to capture current and valid data from the coaching staff and the athletic director. Informal observations were conducted in order to gather rich data of interactions between coaches and students. Attendance and academic document data was collected to compare the effectiveness of athletic programs. Finally, semi structured interviews were utilized to gather opinions and perspectives of the coaches in regards to the athletic program. The findings from data analysis revealed that the male athletic department experienced low participation numbers due to a lack of student's interest and a harmful climate created by the athletics director and coaching staff. The study revealed that the students were heavily involved in extracurricular activities. However, a small percentage of these students were involved in boy's athletics. The athletic program lacked a clear vision with aligned goals. This, along with the toxic working environment, contributed to the toxic culture of the male athletic program.
\end{abstract}

\section{Keywords}

Rural Schools, Program Evaluation, Administrative Leadership, Culture 


\section{Introduction}

Researchers frequently compare the profession of education to a "revolving door" (Ingersoll, 2001). Turnover is high, however it is particularly high in teaching fields such as special education, mathematics, science, as well as the coaching arena of rural, isolated schools (Ingersoll, 2001). This can negatively impact the climate of a campus or program, and when climate is low or toxic, student participation can be negatively affected (Scherer, 2005). Program evaluation can have the potential to positively impact culture and climate for both students and teachers. Program evaluation is a practical endeavor and is used to provide information that can be used to improve the operational environment of specific programs (Barker, 2003).

Quite often social service programs are evaluated because of a need to be accountable to a sponsoring or funding agency, or because competition for scarce funds requires that only one program can be funded. Program evaluation is needed whenever new interventions are required because there is a perception that a program could be improved. Researchers evaluate on those occasions when it is important to have some objective assessment or feedback about the worth of our social programs (Royse, Thyer, \& Padgett, 2010).

Qualitative methods have become central to program evaluation. Qualitative methods are empirical and systematic, relying on careful documentation and analysis grounded in data. The advantage of a qualitative approach is that it allows the researcher to examine program morale, executive decision-making, and student perspectives without relying on structured data collection necessitated by quantitative designs (Royse et al., 2010). By digging deeper and more sensitively, the chances of discovering unanticipated but meaningful insights into a program's inner workings are increased significantly.

The purpose of this study was to analyze the male student population at West Texas Middle School in order to determine why the majority of male students at West Texas Middle School do not participate in the athletic program. Due to this challenge within the male athletics program, the goal of this study is to develop an intervention plan that would:

1) Increase participation within the boys' athletic program;

2) Increase community involvement within the boys' athletic program; and

3) Reestablish pride of the male students within the boys' athletic program.

Currently, there are seven male students in the seventh grade, fifteen in the eighth grade, four in the ninth grade, four in the tenth grade, eleven in the eleventh grade, and seven in the twelfth grade for a total of 48 male students. The male student population makes up $42 \%$ of the total number of students enrolled in the junior high and high school. Within the athletics department, we have six boys participating in basketball and eight participating in off-season activities in grades $9-12$. The organization of the basketball team includes one freshman, two sophomores, two juniors, and one senior. The off-season athletes include two freshmen, two sophomores, four juniors, and one senior. The percentage of 
male athletic participation is $52 \%$ in the high school. However, there are currently fifteen males in junior high athletics, comprising 68\% participation. Due to these unusually low participation percentages, the research questions for this study are:

- Why are male students not participating in athletic programs at West Texas Middle School?

- Does the climate of the male athletic program cultivate and encourage participation?

\section{Literature Review}

Litwin \& Stringer (1968) defined climate as a set of measurable assets of the organization's environment that is either directly or indirectly perceived by the employees who work within the organizational environment that influences or motivates their behavior. School climate is the experience that is greater than the individual within a school. A leader's ability to engage and connect has a positive or negative impact and effectiveness of the organization (Cohen, McCabe, Michelli, \& Pickeral, 2009). The climate of an organization is the sum of perceptions of those who work in the organization. Climate within an organization or program can arouse motivation, causing behavior that results in satisfaction, productivity or performance, and retention. Litwin \& Stringer (1968) identified nine characteristics or dimensions of climate defined as: 1). Structure: feelings employees have about constraints, rules, regulations, and procedures; 2). Responsibility: feeling of being your own boss; 3). Reward: feeling of being rewarded for a job well done, perception of fairness; 4). Risk: feeling that is acceptable to be a risk-taker; 5). Warmth: feeling of being well-liked and prevalence of friendly social and informal social groups; 6). Support: feeling of mutual support from all levels; 7). Standards: feeling represented in decision making and valued for performance; 8). Conflict: feeling of wanting to hear different opinions and recognizing problems publicly; 9). Identity: feeling you are a valued team member.

Educators and leaders alike have recognized the significance of school climate for over a century. However, it wasn't until the 1970s that the topic of school climate began to be a focus of educational research. There is no shared definition for school climate that exists. In fact, a range of terminology is utilized for climate such as atmosphere, feelings, tone, setting, and many other terms. Pepper \& Thomas (2002) defined climate as the environment in which one works and learns as having an impact on their production. The overall feeling of the program or organization exists where collaboration between teachers and coworkers, development of common goals, mutual support and constructive feedback. Razik \& Swanson (2010) described an organizations overall attitude as climate; the attitude of members of the organization is a result of climate.

The common themes within the various definitions involve building community and fostering teacher development. The environment in which educators work and students learn has an important effect on productivity and perfor- 
mance. The school environment, or school climate, is a critical element in our society and has an impact on our society's future. School environment can have a positive or negative effect on the people who work there, directly having an impact on student learning (Pepper \& Thomas, 2002). The organization or program leader's means of communication should be one that is defined by the program's values, and one of which decision making is open for stakeholders. Effective leaders know how to respond to the many complex decisions that have potential to drive stakeholders in many directions ensuring decisions are rooted in the program's core values (Razik \& Swanson, 2010).

Professionals working within a positive climate are engaged and respected by the leader and as a result gain satisfaction from the learning that is fostered. Teachers contribute to the organizational and physical operations of the school. The climate experience goes beyond one's individual experience to describe the collective phenomenon, which is greater than an individual experience (Cohen, Taylor, Zonta, Vestal, \& Schuster, 2007). The phenomenon of a greater individual experience can be compared to a study conducted by Graham \& Haidt (2010) that found individuals involved in religious communities to be happier due to the sense of community and belonging. The establishment of a sense of community within an organization can improve climate (Graham \& Haidt, 2010).

Although the literature is proactive about the impacts of culture on student participation within extracurricular programs, the methodological problems presented with such literature is that research conducted are typically on urban campuses with much larger populations than West Texas Middle School. This discrepancy can produce significantly different results than what we are expecting to find. After analyzing the literature, my leading question is how such research would impact or reflect findings from a rural or isolated school district? However, the findings produce many similarities and differences that will be greatly beneficial to this study.

\section{Methodology}

To understand more fully the athletics department as an organization, the corporation itself must be considered an open systems model. An open systems approach acknowledges that organizations are embedded in multiple environments, both technical and institutional, to which the organization must respond. Technical and institutional environments for secondary education and athletics itself are complex due to the multiple populations that they serve, which include parents, alumni, and local/state boards of education. Individuals involved internally include faculty, staff, and students. Each group presents their own demands for organizational adaption that best fit their needs (Bastedo, 2007). The community of West Texas is a high poverty, low-income society with an open systems model in and of itself. As of the 2010 census, $40 \%$ of women who have children between the ages of six and seventeen do not have a husband present in the household (United States Census Bureau, 2010). The researcher used the da- 
ta collection methods to gather rich, specific data from the participants. These methods of data collection were significantly important in determining whether this theory was trustworthy or unreliable.

The participants that were included in this study were the male student population in grades seven through twelve and the athletic coaching staff. There are 23 male students in the seventh grade and 25 male students in the eighth grade. The male students participated in the questionnaire and informal observation portions of data collection. The athletic coaching staff currently includes the athletic director, the head football coach, and the head basketball coach. The coaching staff was involved in the structured interviews and the informal observation portions of data collection. The students and coaches were selected because the study focuses on using qualitative methodology as a means for program evaluation of the male athletic program.

This particular study was classified as both a case study and a program evaluation due to the nature of the study containing elements of both paradigms. A case study, as defined by Shah \& Al-Bargi (2013: p. 258), is "an approach that employs in-depth investigation of any social phenomenon, using various sources of data". Royse, Thyer, \& Padgett (2010: p. 2) describe a program evaluation as a mission to provide information that can be used to improve social programs. The researcher, as well as campus administrators, hopes that the methodology used for this study can be replicated and applied to similar research situations on campus.

The instruments that the researcher used to collect data were student questionnaires, structured interviews, formal observations, and attendance/academic data documents. The guiding principle behind the data collection process is that "the information collected should be compelling enough to convince any skeptic" (Sagor, 1992: p. 28). These methods were selected because of the nature of the study and reliability of the data that can be provided to the researcher.

The student questionnaire was administered to the male student population under a controlled setting that would guarantee trustworthiness of the data. A questionnaire was selected for data collection because of the possibility for collecting rich data straight from the student population. Within the athletics department, they had six boys participating in basketball and eight participating in off-season activities in grades $9-12$. The organization of the basketball team currently includes one freshman, two sophomores, two juniors, and one senior. The off-season athletes currently include two freshmen, two sophomores, four juniors, and one senior. The percentage of male athletic participation is $52 \%$ in the high school. However, there are currently fifteen males in junior high athletics, comprising $68 \%$ participation. The questionnaire included open-ended responses as well as multiple-choice questions. Examples of questions from the questionnaire include, "Are you currently in athletics?" and "If no, why do you choose not to participate in athletics?" (See Appendix A for more specific examples of the questions on the student questionnaire). Data collected from the questionnaire was used to develop themes or trends in order to determine pat- 
terns within student involvement. In order to ensure trustworthiness, neither the coaching staff nor the athletic director was involved in the creation and administration of the questionnaire to the student athletes. It was the researcher's belief that their presence would have created an intimidating atmosphere and could have possibly influenced some of the answer choices by the students. The mode of administration helped to ensure the trustworthiness of the data collected from the student questionnaire.

Structured group interviews were conducted in order to capture current and valid data from the coaching staff and the athletic director (See Appendix B for examples of questions from the group interview). Data was collected from a variety of individuals, as they had a unique perspective and their own way of contributing to the study. The athletic director of the West Texas athletics program has been with the school for six years, however, only two cumulative years as the athletic director and superintendent of the district. He was selected for this study as he made all final decisions in regards to the boys' and girls' athletic programs. The boys' athletic program contains two coaches that assist each other in various sports. The coaches selected for this study were the head football and head basketball coach. The head basketball coach was an experienced educator with eleven years of total experience and two years as a head coach. The head football coach has served as both a head football and head track coach with thirty years of total experience, all of which was served at West Texas Middle School. The interview was recorded and transcribed. A copy of the transcription was electronically mailed to each participant to confirm responses to the questions.

During a forty-five minute time period (athletic period), informal observations were conducted. The first observation began in the coach's office, recording interactions between the coaching staff. This small observation was fifteen minutes in length. The second observation was performed on the football field and was focused on recording interactions between the coaching staff and the athletes. Data was also collected that focused on the addition and/or removal of students into the athletic program. Attendance and academic document data was collected to compare the effectiveness of athletic programs. According to the Family Educational Rights and Privacy Act (FERPA), schools are allowed to disclose personal student information, without consent, under the condition that an organization or researcher is conducting certain studies for or on behalf of the school (FERPA, 2014). The attendance and academic data of student athletes was analyzed at each grade level, and was compared to students that do not participate in athletics. Data collected from all three methods was disaggregated and interpreted by the researcher. Due to the researcher's lack of direct influence or participation in the athletic program, the data is trustworthy. However, due to the group interview structure that was conducted, it is the researcher's belief that the presence of the athletic director among the other coaching staff members created an atmosphere of intimidation, whether he meant for it to or not. This atmosphere may have created short and unreliable responses from the others coaches. This causes the researcher to question the trustworthiness of the inter- 
view data collected. The researcher reviewed the data and searched for trends that were consistent across figures collected from all four modes.

\subsection{Trustworthiness}

In order to ensure trustworthiness of the data collected from the methods discussed, triangulation of data was used with the data collection techniques. Triangulation ensures that the data and themes developed from the data are credible and dependable. A transcription of the group interview were created and electronically mailed to the participants for member checks. The researcher created an audit trail by numbering the lines of the interview transcription and the observation field notes. Yellow and green highlighters were used to code key words and themes found within the transcriptions and observation notes. This confirmed the reliability and trustworthiness of the data and themes that were found.

An obvious strength of the data sources being used was that they all contributed in different ways to the study. The student athletes were the active participants while the coaching staff and athletic director provided their unique perceptions and opinions to the study. Another obvious strength was the current number of years of experience that the coaching staff and athletic director have. They brought a variety of experiences and knowledge that significantly contributed to the study. A clear weakness of the data sources was that they were focused on one campus of a specific district. This study did not involve other campuses of other school districts. Because this study was very narrow in scope and focused on one campus, a similar study on a different campus may produce different results.

\subsection{Researcher Information/Bias}

The researcher was the current administrator (principal) of the campus hosting the study. Prior to accepting the administrator position, the researcher was an assistant coach and social studies teacher for four years before becoming the head basketball coach of the athletic program that was analyzed. Even though the researcher had no involvement within the athletic program, his prior history with the program created some bias within the scope of this study. The administrator/researcher was required to attend all athletic events, thus creating bias that the athletic program was successful. However, the researcher has left the campus under study and accepted employment on another campus within a separate school district.

\section{Findings}

Open coding was utilized in order to label concepts and define and develop categories based upon their properties and dimensions. By utilizing open coding within this study, it allowed the researcher to open up the text and expose the meaning, thoughts, and ideas within it. This method created more organization 
of data and confirmability of the themes that emerged.

Two themes emerged from the analyzed data:

1) A lack of interest of the students to participate in the athletic program; and

2) Harmful conduct of the coaching staff within the athletic program.

Data collected from the student questionnaire, informal observation, and documentation data aided in developing the first theme. It was found from the student questionnaire that $40 \%$ of students that do not participate in athletics listed "lack of interest" as their primary factor (See Figure 1 for the percentage bar graph). This numerical percentage aided in disproving the researcher's original theory. The theoretical framework that drove the study was that students do not participate in athletics due to their necessity to work after the school day in order to facilitate income for their household. Data collected from the informal observation also helped develop the first theme. At one point during the practice at the football field, one of the athletes began to walk off the field toward the dressing room. The head coach stopped him and asked, "Where are you going? Why are you leaving? We have not finished with practice." The student replied, "There is a concert in Lubbock that me and my girlfriend (sic) are going to. I have to go home to get ready." This clearly shows a lack of interest in participating in the program. It was also observed that a few of the athletes that were standing on the sideline (not participating in a drill being conducted) began discussing other extracurricular activities that they were missing in order to "just stand on the sideline during practice and not do anything". This caused the researcher to wonder how many male students were involved in other extracurricular activities, not just boys' athletics. The researcher then concluded that it was necessary to collect student schedule documentation data instead of attendance/academic records. Once this data was collected and analyzed, it was concluded that $92 \%$ of male students participate in at least one extracurricular activity. However, only $52 \%$ are in boys' athletics. Extracurricular activities on the high school campus include choir, orchestra, electronics, robotics, archery, Civil Air Patrol, chess, University Interscholastic League (UIL) academic competitions, cheerleading, agriculture woodworking, and engine repair.

The second theme that was developed from the data was that the conduct of the coaching staff was harmful to the climate of the program. It was reported from the student questionnaire (Figure 1) that $8 \%$ of the students that do not participate in athletics do so because of a lack of communication with parents. The group interview also shows a lack of direction for the program among the coaching staff. When the researcher asked the staff, "What do you think about the current goals of the athletic program?", "Coach C" responded, "The goals are excellent. Both programs are working towards a common goal that is to bring our program back on top." However, "Coach A" responded with, "The current athletic goals for our athletic program are soft..." The researcher followed up the question with, "May I have a copy of the athletic goals that you have in place?" The staff laughed and "Coach A" stated that they do not have a copy of the goals available at this time. It was noted during the first observation that there was not 


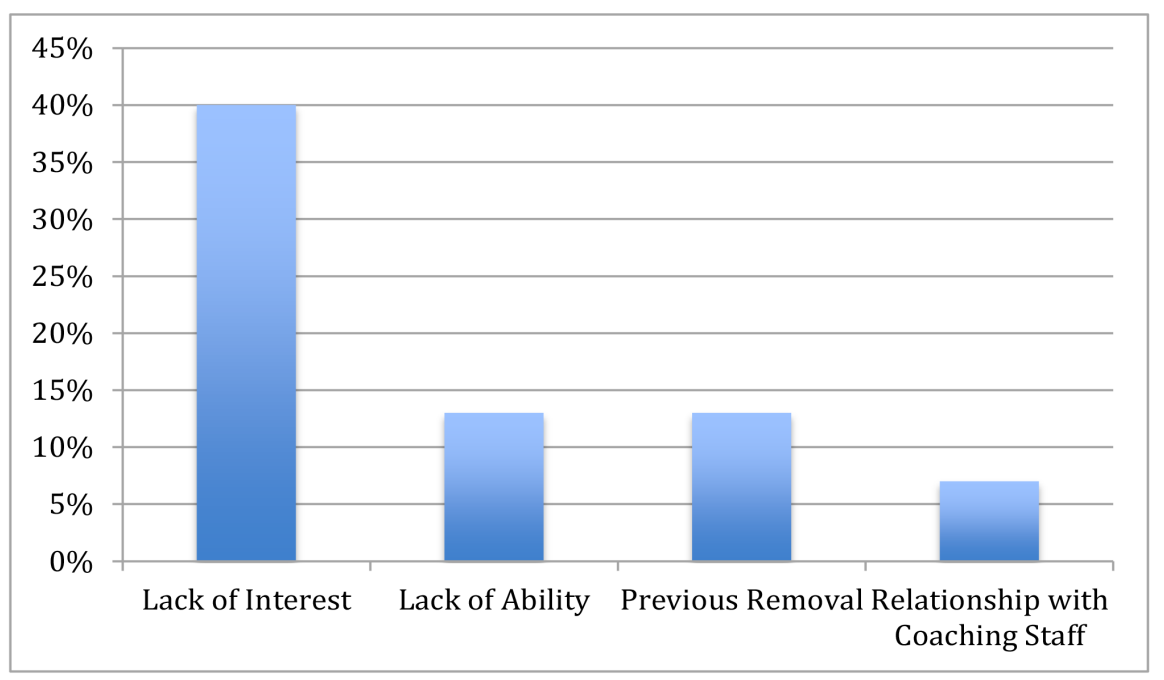

Figure 1. Questionnaire themes.

a list of goals posted in the coaches' office or in the athletes' locker room. It was also noted that there is not a mission or vision statement present in the coach's office or athlete's locker room. Before the staff left the coaches' office for the practice field, the "Coach C" asked "Coach B" for a copy of the day's practice schedule. The head coach did not have one available and stated, "Time is a luxury that I don't have." It was noted that the assistant coach seemed agitated by the response of the head coach.

\section{Conclusion}

Data revealed that the students were heavily involved in extracurricular activities. However, a small percentage of these students were involved in boy's athletics. Numerically, forty-four of the forty-eight students that were administered the questionnaire were involved in at least one extracurricular activity. The male student population was more involved in extracurricular activities than the national average (Cadwallader, Wagner, \& Garza, 2004).

The data also revealed a clear disconnect among the coaching staff. This disconnect was at the time having a negative impact on the culture and climate of the boy's athletic program. Deal \& Peterson (2009) found that elements of a toxic culture and climate include no shared sense of purpose, negative relationships, destructive groups, and no sense of trust or caring. These elements were found within the data that was collected. It is the recommendation of the researcher that the coaching staff collaboratively develop a set of common goals as well as a shared mission and vision statement. By doing this, the coaching staff could improve performance by fostering a shared system of norms, folkways, values, and traditions. These infuse the enterprise with passion, purpose, and a sense of spirit (Deal \& Peterson, 2009).

\section{About the Author}

Matthew Birdwell currently serves as the high school principal for Perryton In- 
dependent School District in Perryton, Texas. Mr. Birdwell is a doctoral candidate in the Department of Curriculum \& Instruction at Texas Tech University with plans to graduate in May 2018. The title of his dissertation is A Qualitative Study of Implementation and Sustainability Factors of Professional Learning Communities on Campus Accountability and Improvement. His research includes professional learning communities (PLC), job embedding professional development, rural schools and education, school culture and climate, and classroom assessment and instruction models. Mr. Birdwell's interests include reading, writing, and spending time with his family.

\section{References}

Barker, R. (2003). The Social Work Dictionary (5th ed.). Washington, DC: NASW Press.

Bastedo, M. (2007). Sociological Frameworks for Higher Education Policy Research. Baltimore, MD: Johns Hopkins University Press.

Cadwallader, T., Wagner, M., \& Garza, N. (2004). Participation in Extracurricular Activities. National Logitudinal Transition Study, 2. http://www.nlts2.org/reports/2003_04-2/nlts2_report_2003_04-2_ch4.pdf

Cohen, D. A., Taylor, S. L., Zonta, M., Vestal, K. D., \& Schuster, M. A. (2007). Availability of High School Extracurricular Sports Programs and High-Risk Behaviors. Journal of School Health, 77, 80-86. https://doi.org/10.1111/j.1746-1561.2007.00171.x

Cohen, J., McCabe, L., Michelli, N. M., \& Pickeral, T. (2009). School Climate: Research, Policy, Practice, and Teacher Education. The Teachers College Record, 111, 180-213.

Deal, T., \& Peterson, K. (2009). Shaping School Culture: Pitfalls, Paradoxes, and Promises. San Francisco, CA: Jossey-Bass.

Family Educational Rights and Privacy Act (FERPA) (2014). Family Policy Compliance Office. http://www2.ed.gov/policy/gen/guid/fpco/ferpa/index.html

Graham, J., \& Haidt, J. (2010). Beyond Beliefs: Religions Bind Individuals into Moral Communities. Personality and Social Psychology Review: An Official Journal of the Society for Personality and Social Psychology, Inc., 14, 140-150. https://doi.org/10.1177/1088868309353415

Ingersoll, R. M. (2001). How Distributed Leadership Can Make a Difference in Teachers' Organizational Comment? A Qualitative Study. Teaching and Teacher Education, 26, 565-575.

Litwin, G. H., \& Stringer Jr., R. A. (1968). Motivation and Organizational Climate (Vol. VIII, p. 214). Oxford: England Harvard University.

Pepper, K., \& Thomas, L. H. (2002). Making a Change: The Effects of the Leadership Role on School Climate. Journal of Education for Business, 84, 2-6.

Razik, T. A., \& Swanson, A. D. (2010). Fundamental Concepts of Educational Leadership and Management. Boston, MA: Pearson.

Royse, D., Thyer, B., \& Padgett, D. (2010). Program Evaluation: An Introduction. Belmont, CA: Wadsworth Cengage Learning.

Sagor, R. (1992). How to Conduct Collaborative Action Research. Alexandria, VA: Association for Supervision and Curriculum Development.

Scherer, M. (2005). Keeping Good Teachers. Princeton, NJ: Recording for the Blind \& Dyslexic.

Shah, S. R., \& Al-Bargi, A. (2013). Research Paradigms: Researcher's Worldviews, Theo- 
retical Frameworks, and Study Designs. Arab World English Journal, 4, 252-264.

United States Census Bureau (2010). Community Facts-Find Popular Facts (Population, Income, etc.) and Frequently Requested Data about Your Community. http://factfinder2.census.gov/faces/nav/jsf/pages/community_facts.xhtml 


\section{Appendix A}

Student Questionnaire

(Answer Yes to \#2)

1) What grade are you in?

A) $7^{\text {th }}$ Grade

B) $8^{\text {th }}$ Grade

C) $9^{\text {th }}$ Grade

D) $10^{\text {th }}$ Grade

E) $11^{\text {th }}$ Grade

F) $12^{\text {th }}$ Grade

2) Are you currently in athletics?

A) Yes

B) No

3) If yes, what sports do you currently play? (Mark all that apply.)

A) Football

B) Basketball

C) Track

D) Cross Country

E) Tennis

F) Golf

4) If you do not play a particular sport, why?

A) I do not like the sport.

B) I do not think I am very good at that particular sport.

C) I do not have time to practice for that particular sport.

D) My parents will not let me play that sport.

E) I do not like the coaching staff.

F) Medical (Injuries) Issues.

G) Other... Explain...

H) Does Not Apply.

5) If you answered (C) on question 3, why do you not have time to practice for that particular sport?
A) Academic (Grade) Issues.
B) Employment (Job) Opportunities.
C) Home (Family) Issues.
D) Other... Explain...
6) If you answered (E) on question 3, what do you not like about the coaching staff?
A) Conduct (Behavior during the game.)
B) Attitude (Feelings toward individual player or player's performance.)
C) Philosophy (Playing time, coaching strategies, etc.)

(Answer "No" to \#2)

2) Are you currently in athletics?
A) Yes
B) $\mathrm{No}$ 
3) If no, why do you choose not to participate in athletics?

A) I am not interested.

B) I do not think I am athletic enough to play sports.

C) My parents will not let me.

D) Employment (Job) Opportunities.

E) Academic (Grades) Issues.

F) Medical (Injuries) Issues.

G) I was removed previously from the athletic program.

H) I do not like the coaching staff.

I) Other... Explain...

4) If you answered (C) to question \#2, why will your parents not let you participate?

A) Because of my grades.

B) Because of my behavior at school.

C) Because they want me to work.

D) Because they do not like athletics.

E) Because they are afraid I might get hurt.

F) Because they do not like the coaching staff.

G) Other... Explain...

5) If you answered (E) to question \#2, what can the coaching staff do to help you with your grades in the classroom?
A) Assign me to tutorial blocks on Fridays after lunch.
B) Create tutoring groups within the boy's athletic program.
C) Other... Explain...
6) If you answered $(\mathrm{H})$ to question \#2, what do you not like about the coaching staff?
A) Conduct (Behavior during a game.)
B) Attitude (Feelings toward an individual player or player's performance.)
C) Philosophy (Playing time, coaching strategies, etc.)
7) If you answered (G) to question \#2, why were you removed from the athletic program?
A) Grades.
B) Behavior.
C) Drugs.
D) Other... Examples...

8) What changes could be made to the athletic program that would persuade you to participate?
A) Facilities.
B) Equipment. (Workout gear, uniforms, water bottles, etc.)
C) Conduct of the coaching staff.
D) Practice time. (Practice before school instead of after school.)
E) Other... Explain... 


\section{Appendix B}

Interview Questions

1) What do you recall about the current goals of the athletic program?

2) How do you feel about the boy's athletic staff working toward the goals?

3) What is your opinion of the quality of the boy's athletic goals?

4) Should the goals be revised? Why?

5) In your opinion, why does the boy's athletic program have such low participation numbers?

6) How important do you think a mission or vision statement would be for the athletic program?

7) What things could the coaching staff change to increase numbers in the boy's athletic program?

8) Ultimately, how does the future look for Lorenzo boy's athletics?

9) How would you rate the current condition of the boy's athletic program? Explain.

Poor 1234 Great 